\title{
Brain-Derived Neurotrophic Factor Up-Regulation by the Methanol Extract of Foxtail Millet in Human Peripheral Cells
}

\author{
Kensuke NAKAJIMA $^{1}$, Shigeru OISO ${ }^{1,2}$ and Hiroko KARIYAZONO ${ }^{1,2, *}$ \\ ${ }^{1}$ Department of Pharmacy, Faculty of Pharmaceutical Sciences, Nagasaki International University, \\ 2825-7 Huis Ten Bosch, Sasebo, Nagasaki 859-3298, Japan \\ ${ }^{2}$ Graduate School of Pharmaceutical Sciences, Nagasaki International University, \\ 2825-7 Huis Ten Bosch, Sasebo, Nagasaki 859-3298, Japan
}

(Received October 17, 2019)

\begin{abstract}
Summary Brain-derived neurotrophic factor (BDNF) plays important roles in synaptic plasticity and neuronal differentiation. The neurotrophic hypothesis of depression, which suggests that reduced BDNF in the hippocampus underlies depression, has attracted increasing attention. Stress, a major cause of depression, leads to decreased BDNF levels, and administration of BDNF into the hippocampus shows an antidepressant effect. BDNF is synthesized in peripheral tissues as well as in the brain. Since BDNF crosses the bloodbrain barrier, intake of food ingredients that elevate BDNF in peripheral tissues may be useful for the prevention and treatment of depression. However, no screening method for BDNF up-regulators in peripheral tissues has been reported. In this study, we revealed that ACHN human kidney adenocarcinoma cells secreted BDNF. In addition, we demonstrated that the methanol extract of foxtail millet up-regulated BDNF levels in ACHN cells. Our results indicate that ACHN cells could be useful in the screening for peripheral-BDNF up-regulators, and that foxtail millet may have the potential to elevate BDNF levels in peripheral tissues.
\end{abstract}

Key Words BDNF, depression, neurotrophic hypothesis, food substance, blood-brain barrier, ACHN cell

Depression is a common life-threatening disease. It has become the fifth most serious disease injuring human health worldwide (1). Despite the severe impact of depression, there is no effective antidepressive preventative method. Furthermore, commercially available antidepressants (based on the monoamine hypothesis) are insufficiently effective in nearly $30 \%$ of patients with depression (2).

The neurotrophic hypothesis of depression posits that a deficiency of brain-derived neurotrophic factor (BDNF) in the hippocampus underlies depression (3). BDNF, a member of the neurotrophin family, is involved in the survival and synaptic plasticity of neurons in the adult central nervous system (CNS) (4). BDNF is synthesized as a precursor peptide, pre-pro-BDNF (5). Some proprotein convertases (PCs) such as furin, $\mathrm{PC} 1, \mathrm{PC} 5, \mathrm{PC} 7$, and PACE4 are involved in processing to mature $\operatorname{BDNF}(6,7)$.

Stress associated with the onset of depression leads to decreased BDNF mRNA in the hippocampus of rodents $(8,9)$, and bilateral infusion of BDNF into the hippocampus of rats elicits a rapid antidepressant-like effect (10). Therefore, the elevation of BDNF levels in the brain is considered as a new strategy for depression treatment.

BDNF is expressed not only in the brain but also in various peripheral tissues, including the bladder, pancreas, kidney, and liver $(11,12)$. BDNF can cross the

\footnotetext{
*To whom correspondence should be addressed.

E-mail: karihiro@niu.ac.jp
}

blood-brain barrier (BBB) (13). Peripheral administration of BDNF elevated BDNF protein levels as determined by ELISA in the hippocampus by approximately 25\% and showed antidepressant-like effects in mice (14). Furthermore, it has been reported that the serum BDNF levels of depressed patients are lower than those of control subjects, and BDNF concentration and the severity of depression symptoms are significantly negatively correlated (15). From the above findings, food substances having BDNF up-regulating effects in peripheral tissues may exert prophylactic and therapeutic effects against depression. However, there are no screening methods for BDNF up-regulators in peripheral tissues, and food substances with BDNF up-regulating effects have not been identified. In the present study, we aimed to identify peripheral cell lines that produce and secrete BDNF to explore BDNF up-regulators. Furthermore, we investigated whether cereal methanol extracts, such as foxtail millet, proso millet, and black rice, have up-regulating effects using peripheral cell lines.

\section{Materials and Methods}

Reagents and materials. Dulbecco's modified Eagle's medium (DMEM), RNAlater, and TRIzol were purchased from Life Technologies (Carlsbad, CA, USA), and ReverTra Ace was purchased from Toyobo (Osaka, Japan). AmpliTaq Gold 360 Master Mix was obtained from Applied Biosystems (Foster City, CA, USA). The BDNF, Human, Mouse, Rat ELISA Kit was purchased from 
Aviscera Bioscience Inc. (Santa Clara, CA, USA). The primers used in this study (Table 1) were obtained from GeneNet (Fukuoka, Japan) or Greiner Japan (Kanagawa, Japan). Foxtail millet, proso millet, and black rice were purchased from Nogyo Keiei Kenkyujo (Kanagawa, Japan). Methanol, 3-(4,5-dimethyl-2-thiazolyl)-2,5-diphenyl-2H-tetrazolium bromide (MTT), dimethyl sulfoxide (DMSO), and other reagents were obtained from Wako Pure Chemical Industry (Osaka, Japan), unless otherwise indicated.

Cell culture. We obtained the following cells from the JCRB cell bank (Osaka, Japan), MIA PaCa-2 (human

Table 1. Primers used in PCR.

\begin{tabular}{cl}
\hline Gene & \multicolumn{1}{c}{ Primer pairs } \\
\hline \multirow{2}{*}{ BDNF } & F:5'-TTTGGTTGCATGAAGGCTGC-3' \\
& R:5'-GCCGAACTTTCTGGTCCTCA-3' \\
\multirow{2}{*}{ Furin } & F:5'-GAAGTGCACGGAGTCTCACA-3' \\
& R:5'-CCGCCATGTGAGGTTCTTAT-3' \\
PC1 & F:5'-TTGGCTGAAAGAGAACGG-3' \\
& R:5'-ACTTCTTTGGTGATTGCTTTG-3' \\
PC5 & F:5'-TGCGCTCCATCTACAAAG-3' \\
& R:5'-CATTGCAGTGGTCTGGTC-3' \\
PC7 & F:5'-ATCATTGTCTTCACAGCC-3' \\
& R:5'-AAGCCTGTAGGTCCCTC-3' \\
PACE4 & F:5'-CTATGGATTTGGTTTGGTGGAC-3' \\
& R:5'-AGGCTCCATTCTTTCAACTTCC-3 \\
GAPDH & F:5'-GTGTGAACCATGAGAAGTATG-3' \\
& R:5'-TTTGGCAGGTTTTTCTAGACG-3' \\
\hline
\end{tabular}

F: forward, R: reverse. pancreatic cancer), Hep G2 (human hepatocarcinoma), and T24 (human urinary bladder carcinoma). ACHN (human kidney adenocarcinoma) cells were supplied by Dr. Ryuji Ikeda (Department of Pharmacy, University of Miyazaki Hospital, Japan). All cells were cultured in DMEM containing $10 \%$ fetal bovine serum at $37^{\circ} \mathrm{C}$ in a humidified atmosphere of $5 \% \mathrm{CO}_{2}$.

RT-PCR. Total RNA was extracted from cells with TRIzol reagent and reverse-transcribed into cDNA with ReverTra Ace. The PCR reaction solutions were prepared to a final volume of $25 \mu \mathrm{L}$ containing $1 \mu \mathrm{L}$ first strand cDNA, 12.5 pmol forward and reverse primers, and 12.5 $\mu \mathrm{L}$ AmpliTaq Gold 360 Master Mix. PCR was performed under the following conditions: an initial denaturation step at $95^{\circ} \mathrm{C}$ for $10 \mathrm{~min}$, followed by 30 cycles of denaturation at $95^{\circ} \mathrm{C}$ for $30 \mathrm{~s}$, annealing at $60^{\circ} \mathrm{C}$ for $30 \mathrm{~s}$, and extending at $72^{\circ} \mathrm{C}$ for $1 \mathrm{~min}$, followed by a final 7 -min extension step at $72^{\circ} \mathrm{C}$.

Measurements of BDNF concentrations in the culture medium. The cells were seeded in 12-well plates in DMEM and cultured for $24 \mathrm{~h}$, followed by two washes with phosphate-buffered saline. Fresh DMEM was added to each well, and the cells were cultured for $24 \mathrm{~h}$, followed by collection of the culture medium in a microtube. The concentration of BDNF in the culture medium was measured with a BDNF ELISA kit. For evaluation of the BDNF up-regulation effect of the test cereals, the BDNF concentration in each well was adjusted for the cell number determined using an EVE automatic cell counter (Ar Brown, Tokyo, Japan). Final concentrations of DMSO in culture mediums with foxtail millet, proso millet, and black rice were $0.25,0.125$, and $0.0625 \%$, respectively.
A

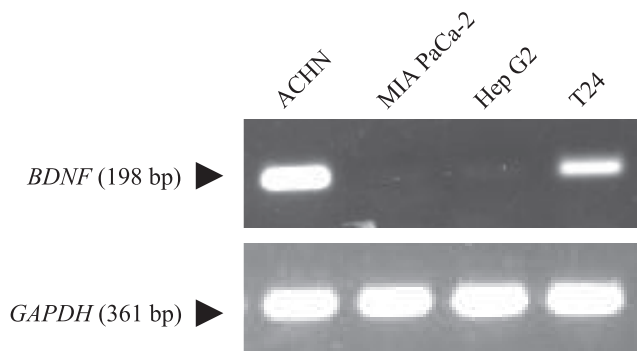

$\mathrm{C}$

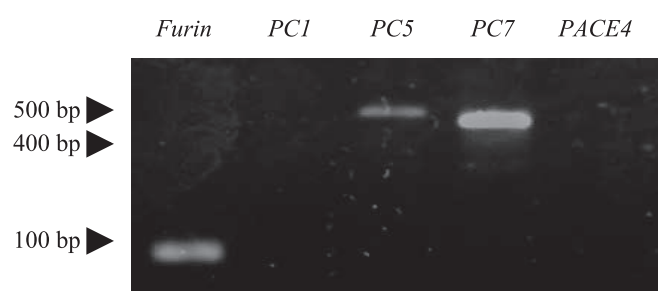

B

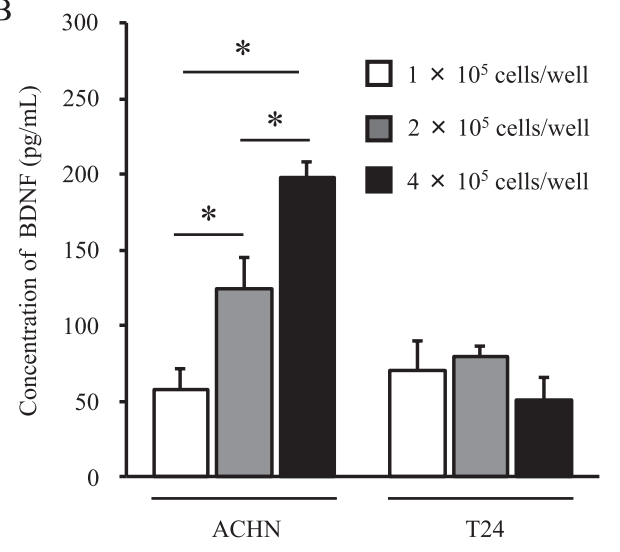

Fig. 1. Identification of the peripheral cells producing and secreting BDNF. (A) Messenger RNA expression of BDNF (upper) and GAPDH (lower) in ACHN, MIA PaCa-2, HepG2, and T24 cells assessed with RT-PCR. The expected amplified DNA fragment sizes were 198 (BDNF) and 361 (GAPDH) base pairs. (B) BDNF concentrations in the culture medium of ACHN and T2 4 cells. Each cell line was seeded in 12-well plates at 1, 2, or $4 \times 10^{5}$ cells/well. BDNF levels were measured by ELISA. Data are expressed as the mean \pm SD $(n=6) .{ }^{*} p<0.05$. (C) Messenger RNA expression of furin, PC1, PC5, PC7, and PACE4 in ACHN cells assessed with RT-PCR. The expected amplified DNA fragment sizes of furin, PC1, PC5, PC7, and PACE4 were 99, 457, 510, 471, and 456 base pairs, respectively. 


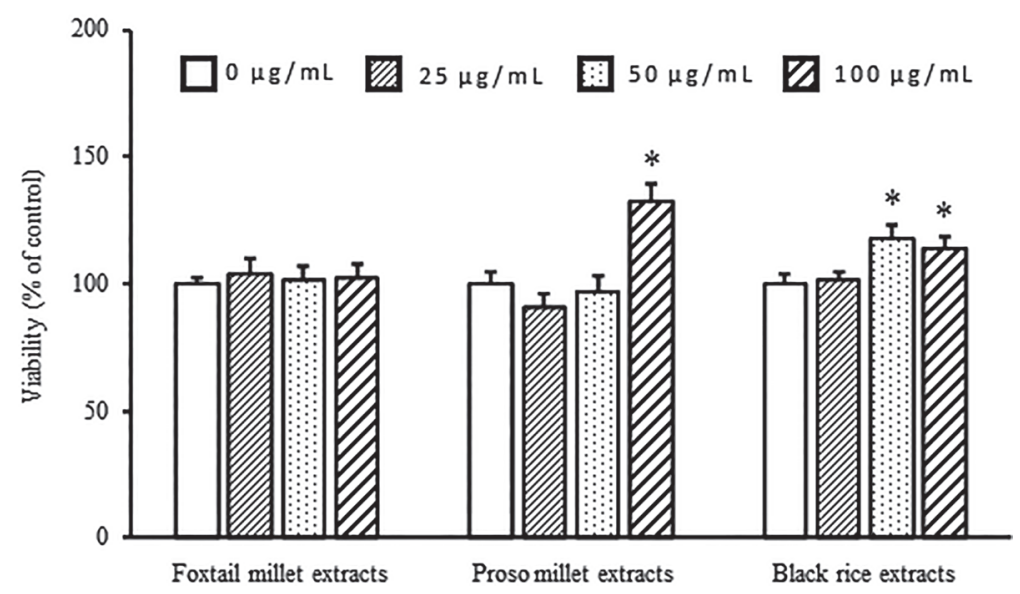

Fig. 2. Viability of ACHN cells treated with the methanol extracts of test cereals. Each value represents the viability relative to that in the control $(0 \mu \mathrm{g} / \mathrm{mL})$. Because $0.25 \%$ of DMSO was present in the culture mediums along with $100 \mu \mathrm{g} /$ $\mathrm{mL}$ of test cereals, $0.25 \%$ of DMSO was added to the control culture mediums. Data are expressed as the mean \pm SD $(n=6)$. ${ }^{*} p<0.05$ vs. control $(0 \mu \mathrm{g} / \mathrm{mL})$.
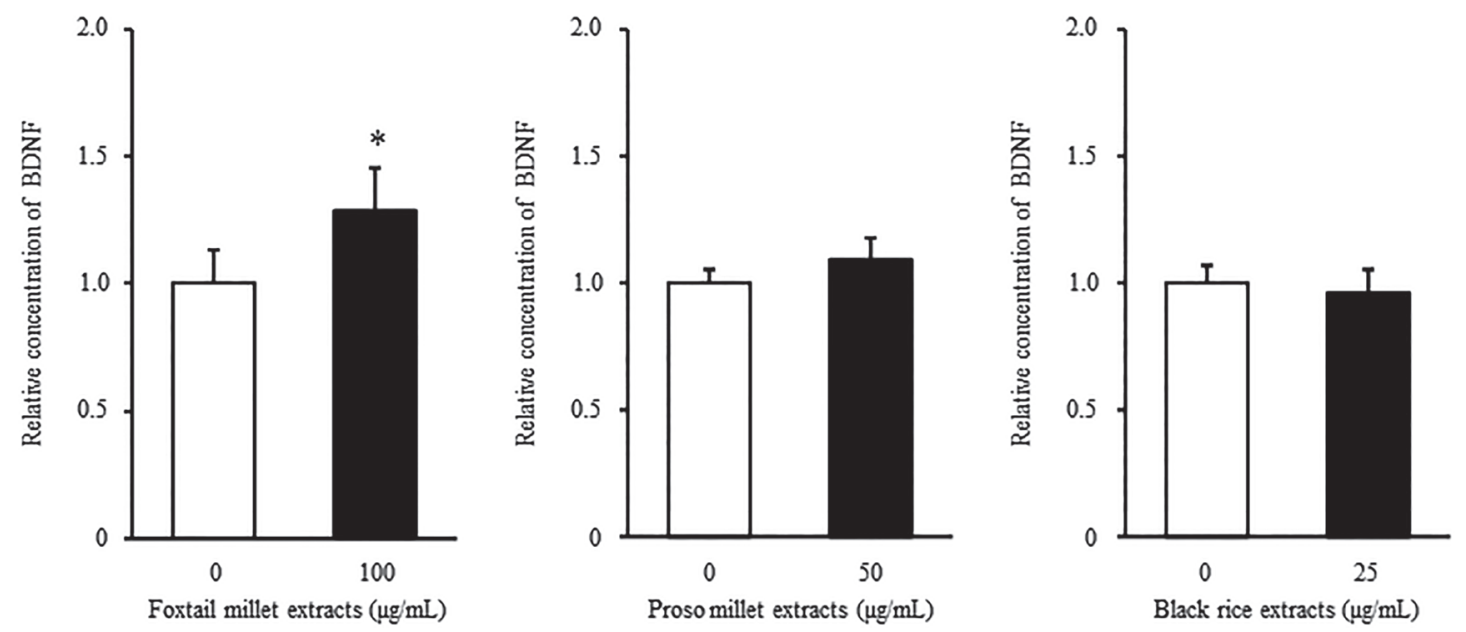

Fig. 3. Relative concentrations of BDNF in the culture medium of ACHN cells treated with the methanol extract of test cereals to compare with the control $(0 \mu \mathrm{g} / \mathrm{mL})$. Culture mediums with foxtail millet, proso millet, and black rice contained $0.25,0.125$, and $0.0625 \%$ DMSO, respectively. The final concentration of DMSO in each control culture medium was the same as that in corresponding culture mediums with the test cereals. Data are expressed as the mean \pm SD $(n=6)$. $* p<0.05$ vs. control $(0 \mu \mathrm{g} / \mathrm{mL})$.

Preparation of cereal methanol extracts. Cereals were crushed by Tube Mill 100 control (Ika, Staufen, Germany). Cereal powder ( $5 \mathrm{~g}$ ) was stirred in $100 \%$ methanol for $24 \mathrm{~h}$ at room temperature. The supernatant was collected by centrifugation at $15,000 \times g, 4^{\circ} \mathrm{C}$, for $10 \mathrm{~min}$. The collected supernatant was dried by spraying nitrogen gas to obtain the cereal methanol extract. The residue was dissolved in DMSO and its concentration was adjusted to $40 \mathrm{mg} / \mathrm{mL}$.

Cell viability assay. The MTT assay was performed as described in our previous study (16). Briefly, the cells were seeded in 96-well plates at $1 \times 10^{4}$ cells/well and cultured for $24 \mathrm{~h}$ in DMEM. Subsequently, the methanol extracts of the test cereal were added to the culture medium at $0,25,50$, and $100 \mu \mathrm{g} / \mathrm{mL}$. After $24 \mathrm{~h}$ of cultivation, MTT was added to each well, and the cells were cultured for an additional $4 \mathrm{~h}$. The forma- zan crystals produced in cells were dissolved in DMSO after removing the culture medium. Optical density at $570 \mathrm{~nm}$ was measured with a Multiskan FC instrument (Thermo Fisher Scientific, Waltham, MA, USA). Values are expressed as the ratio of optical density of treated cells to that of untreated control cells.

Statistical analysis. Values are provided as means \pm standard deviations (SD). Differences between groups were analyzed by two-sample $t$-test or one-way ANOVA, followed by Tukey's test for multiple comparisons. Differences were considered significant at $p<0.05$.

\section{Results and Discussion}

We examined the expression of BDNF mRNA in ACHN, MIA PaCa-2, Hep G2, and T24 cells by RT-PCR. Expression of BDNF was observed in ACHN and T24 cells (Fig. 1A). Next, we investigated whether BDNF 
could be detected by ELISA in a culture medium of ACHN and T24 cells seeded at three densities (1, 2, and $4 \times 10^{5}$ cells/well). BDNF levels in the culture medium of ACHN cells, but not T24 cells, increased in a seeded cell number-dependent manner (Fig. 1B). Additionally, we examined the mRNA expression of enzymes related to the processing of pro-BDNF to mature BDNF in ACHN cells by RT-PCR. ACHN cells expressed the mRNA of furin, PC5, and PC7 (Fig. 1C). Seidah et al. reported that furin is the most efficient $\mathrm{PC}$ for the processing of mature BDNF (6). These results suggest that ACHN cells may be utilized for the identification of BDNF up-regulators in peripheral tissues.

Subsequently, we tried to identify cereals with a BDNF up-regulating effect using ACHN cells. First, the viability of ACHN cells in the presence of cereal methanol extracts was evaluated by an MTT assay to determine their test concentrations. There were no significant differences in the viability of cells treated with foxtail millet up to concentration of $100 \mu \mathrm{g} / \mathrm{mL}$ (Fig. 2). Treatment with proso millet and black rice extracts did not impact cell viability up to $50 \mu \mathrm{g} / \mathrm{mL}$ and $25 \mu \mathrm{g} / \mathrm{mL}$, respectively (Fig. 2). Next, we determined the BDNF concentrations in the culture medium of ACHN cells cultivated with the test cereals at concentrations that did not affect the viability of ACHN cells. Foxtail millet at $100 \mu \mathrm{g} / \mathrm{mL}$ significantly increased BDNF concentrations in the culture medium compared with control (Fig. 3). The other cereals did not affect BDNF concentration in ACHN cells (Fig. 3).

Cereals, such as proso and foxtail millet, have been recognized as potential functional foods; it is known that they have beneficial effects against diabetes and liver disorder $(17,18)$. However, there is little information regarding the effects of cereals on depression. Furthermore, it is unknown whether cereals can upregulate $\mathrm{BDNF}$. In the present study, only foxtail millet, but not proso millet or black rice, up-regulated BDNF. Recently, Stringham et al. showed that dietary zeaxanthin, a common carotenoid found in many vegetables, increased serum BDNF levels in healthy young human subjects (19). Since foxtail millet includes abundant zeaxanthin (20), zeaxanthin may contribute to the BDNF up-regulating effect of foxtail millet. Conversely, the other cereals used in this study reportedly contain little zeaxanthin (21). This difference in zeaxanthin content in the test cereals may be the reason why only foxtail millet showed a BDNF up-regulating effect in this study. To test this hypothesis, it is necessary to investigate the effect of zeaxanthin on BDNF production in ACHN cells and determine the zeaxanthin content in the methanol extracts of proso millet, foxtail millet, and black rice.

In this study, we found that BDNF was produced in ACHN human kidney adenocarcinoma cells. As BDNF can cross the BBB (13), BDNF up-regulators identified using ACHN cells could elicit preventative and treatment effects against depression without passing through the BBB. In addition, BDNF levels in the culture medium of ACHN cells treated with foxtail millet extracts were 1.28-fold higher than those in the control.
It was reported that serum BDNF levels in healthy subjects were approximately 1.21-fold higher than those in depressed patients (22). Therefore, our result indicates that foxtail millet has the potential for treating depression through enhancement of BDNF levels in peripheral tissues. Future in vivo experiments using depression model animals are needed to clarify whether foxtail millet has an antidepressant-like effect with up-regulation of BDNF.

\section{Authorship}

Research conception and design: KN; experiments: $\mathrm{KN}$; statistical analysis of the data: $\mathrm{KN}$; interpretation of the data: KN, SO, and HK; writing of the manuscript: $\mathrm{KN}, \mathrm{SO}$, and HK.

\section{Disclosure of state of COI}

No conflicts of interest to be declared.

\section{Acknowledgments}

This work was supported in part by JSPS KAKENHI (Grant Number 17K12915) and Takano Life Science Research Foundation.

\section{REFERENCES}

1) Korczyn AD, Halperin I. 2009. Depression and dementia. J Neuro Sci 283: 139-142.

2) Papakostas GI, Fava M, Thase ME. 2008. Treatment of SSRI-resistant depression: a meta-analysis comparing within- versus across-class switches. Biol Psychiatry 63: 699-704.

3) Duman RS, Heninger GR, Nestler EJ. 1997. A molecular and cellular theory of depression. Arch Gen Psychiatry 54: 597-606.

4) Tapia-Arancibia L, Rage F, Givalois L, Arancibia S. 2004. Physiology of BDNF: focus on hypothalamic function. Front Neuroendocrinol 25: 77-107.

5) Foltran RB, Diaz SL. 2016. BDNF isoforms: a round trip ticket between neurogenesis and serotonin? J Neurochem 138: 204-221.

6) Seidah NG, Benjannet S, Pareek S, Chretien M, Murphy RA. 1996. Cellular processing of the neurotrophin precursors of NT3 and BDNF by the mammalian proprotein convertases. FEBS Lett 379: 247-250.

7) Wetsel WC, Rodriguiz RM, Guillemot J, Rousselet E, Essalmani R, Kim IH, Bryant JC, Marcinkiewicz J, Desjardins R, Day R, Constam DB, Prat A, Seidah NG. 2013. Disruption of the expression of the proprotein convertase PC7 reduces BDNF production and affects learning and memory in mice. Proc Natl Acad Sci USA 110: 17362-17367.

8) Kikusui T, Ichikawa S, Mori Y. 2009. Maternal deprivation by early weaning increases corticosterone and decreases hippocampal BDNF and neurogenesis in mice. Psychoneuroendocrinology 34: 762-772.

9) Nibuya M, Morinobu S, Duman RS. 1995. Regulation of BDNF and trkB mRNA in rat brain by chronic electroconvulsive seizure and antidepressant drug treatments. J Neurosci 15: 7539-7547.

10) Shirayama Y, Chen AC, Nakagawa S, Russell DS, Duman RS. 2002. Brain-derived neurotrophic factor produces antidepressant effects in behavioral models of depression. J Neurosci 22: 3251-3261. 
11) Endlich N, Lange T, Kuhn J, Klemm P, Kotb AM, Siegerist F, Kindt F, Lindenmeyer MT, Cohen CD, Kuss AW, Nath N, Rettig R, Lendeckel U, Zimmermann U, Amann K, Stracke S, Endlich K. 2018. BDNF: mRNA expression in urine cells of patients with chronic kidney disease and its role in kidney function. J Cell Mol Med 22: 5265-5277.

12) Lommatzsch M, Braun A, Mannsfeldt A, Botchkarev VA, Botchkareva NV, Paus R, Fischer A, Lewin GR, Renz H. 1999. Abundant production of brain-derived neurotrophic factor by adult visceral epithelia. Implications for paracrine and target-derived neurotrophic functions. Am J Pathol 155: 1183-1193.

13) Pan W, Banks WA, Fasold MB, Bluth J, Kastin AJ. 1998. Transport of brain-derived neurotrophic factor across the blood-brain barrier. Neuropharmacology 37: 1553-1561.

14) Schmidt HD, Duman RS. 2010. Peripheral BDNF produces antidepressant-like effects in cellular and behavioral models. Neuropsychopharmacology 35: 2378-2391.

15) Karege F, Perret G, Bondolfi G, Schwald M, Bertschy G, Aubry JM. 2002. Decreased serum brain-derived neurotrophic factor levels in major depressed patients. Psychiatry Res 109: 143-148.

16) Nakajima K, Oiso S, Kariyazono H. 2018. Inhibitory effect of (-)-epigallocatechin-3-O-gallate on octanoylated ghrelin levels in vitro and in vivo. Biol Pharm
Bull 41: 524-529.

17) Nishizawa N, Sato D, Ito $Y$, Nagasawa T, Hatakeyama $Y$, Choi MR, Choi YY, Wei YM. 2002. Effects of dietary protein of proso millet on liver injury induced by D-galactosamine in rats. Biosci Biotechnol Biochem 66: 92-96.

18) Ren X, Yin R, Hou D, Xue Y, Zhang M, Diao X, Zhang Y, Wu J, Hu J, Hu X, Shen Q. 2018. The glucose-lowering effect of foxtail millet in subjects with impaired glucose tolerance: A self-controlled clinical trial. Nutrients 10: E1509.

19) Stringham NT, Holmes PV, Stringham JM. 2019. Effects of macular xanthophyll supplementation on brainderived neurotrophic factor, pro-inflammatory cytokines, and cognitive performance. Physiol Behav 211: 112650 .

20) Zhang LZ, Liu RH. 2015. Phenolic and carotenoid profiles and antiproliferative activity of foxtail millet. Food Chem 174: 495-501.

21) Wurtzel ET. 2004. Chapter five Genomics, genetics, and biochemistry of maize carotenoid biosynthesis. Recent Adv Phytochem 38: 85-110.

22) Karege F, Bondolfi G, Gervasoni N, Schwald M, Aubry JM, Bertschy G. 2005. Low brain-derived neurotrophic factor (BDNF) levels in serum of depressed patients probably results from lowered platelet BDNF release unrelated to platelet reactivity. Biol Psychiatry 57: 1068-1072. 